\title{
Evidence of association between the use of drugs and community-dwelling older people frailty: a cross-sectional study
}

\author{
Marcos Kaic Lopes Alves', Nayara Gomes Nunes Oliveira", Maycon Sousa Pegorari"', Darlene Mara dos Santos Tavares'v, \\ Maria Cristina Soares Rodrigues ${ }^{v}$, Alisson Fernandes Bolina ${ }^{\mathrm{v}}$
}

Universidade de Brasília - Campus Darcy Ribeiro (UnB), Brasília (DF), Brazil

'BSc. Pharmacist, Universidade de Brasília Campus Darcy Ribeiro (UnB), Brasília (DF) Brazil. (D) orcid.org/0000-0003-0808-300X

"PhD. Nurse, Universidade Federal do Triângulo Mineiro (UFTM), Uberaba (MG), Brazil.

(D) orcid.org/0000-0003-4170-8761

'IPhD. Physiotherapist and Adjunct Professor, Physiotherapy Course, Universidade Federal do Amapá (UNIFAP), Macapá (AP), Brazil.

(D) orcid.org/0000-0003-4015-9895

"vphD. Nurse and Associate Professor, Department of Nursing Education and Community Health Nursing Undergraduate Program, Universidade Federal do Triângulo Mineiro (UFTM), Uberaba (MG), Brazil.

(D) orcid.org/0000-0001-9565-0476

vphD. Nurse and Pharmacist, Associate Professor, Universidade de Brasília - Campus Darcy Ribeiro (UnB). Brasília (DF), Brazil.

(D) orcid.org/0000-0003-0206-4238

viphD. Nurse and Adjunct Professor, Universidade de Brasília - Campus Darcy Ribeiro (UnB), Brasília (DF), Brazil.

(D) orcid.org/0000-0002-1364-0176

KEY WORDS (MeSH terms):

Polypharmacy.

Drug interactions.

Potentially inappropriate medication list.

\section{AUTHORS' KEY WORDS}

Older people.

Frail older people.

Polypharmacy among older people.

\begin{abstract}
BACKGROUND: The scientific literature has shown that an association between polypharmacy and frailty exists. However, few studies have also considered drug interactions and the use of potentially inappropriate medications.

OBJECTIVE: To evaluate the association between the use of drugs and frailty among community-dwelling older people.

DESIGN AND SETTING: Cross-sectional study carried out among 580 older people in Uberaba (MG). METHODS: Data were collected at these older people's homes using instruments validated in Brazil. Descriptive, bivariate and binary logistic regression analyses were performed $(P<0.05)$.

RESULTS: Most of these individuals were classified as pre-frail (55.7\%), while $13.1 \%$ were frail. It was found that $31.7 \%$ of them presented polypharmacy, $41.7 \%$ had drug interactions and $43.8 \%$ were using potentially inappropriate medications. In the initial model, polypharmacy (odds ratio, $\mathrm{OR}=1.91$; confidence interval, $\mathrm{Cl}=1.27-2.86)$ and use of potentially inappropriate medications ( $\mathrm{OR}=2.45 ; \mathrm{Cl}=1.68-3.57)$ increased the chance that these older people would be pre-frail or frail. In the final adjusted model, use of potentially inappropriate drugs remained associated with the outcome $(\mathrm{OR}=2.26 ; \mathrm{Cl}=1.43-3.57)$.

CONCLUSION: Use of potentially inappropriate medications was the independent variable that explained the occurrence of frailty in a representative sample of community-dwelling older adults.
\end{abstract}

\section{INTRODUCTION}

Frailty syndrome among older people is related to changes that occur through the human aging process, such as sarcopenia, neuroendocrine dysregulation and immune system dysfunction. ${ }^{1}$ Frail individuals are at increased risk of adverse events and injuries due to falls, which, together with various comorbidities, can cause higher rates of institutional care, hospitalizations and mortality. ${ }^{1,2}$

The aging process can promote physiological changes that cause older people to exhibit distinctive pharmacokinetics, such that they may become more sensitive both to the therapeutic effects and to the toxic effects of drug therapy. ${ }^{3}$ Furthermore, multimorbid conditions require the use of multiple drugs, which is characterized as polypharmacy. This, together with the physiological changes of aging can increase the chances of adverse events among older people. ${ }^{3-6}$ These include the increased levels of pathogenesis within frailty syndrome, as highlighted in the International Frailty Consensus.?

There are several concepts of polypharmacy, although most of them consider it to be the concomitant use of five or more drugs. ${ }^{8}$ This was the concept used in the present investigation. It is important to note that polypharmacy increases the risk of drug interactions (DI), as well as the use of potentially inappropriate medications (PIMs) among older people. ${ }^{3}$ Polypharmacy, therefore, cannot be considered to be the only marker for assessing the quality of drug prescriptions, ${ }^{9}$ which requires consideration of DIs and use of PIMs for clinical care among older people.

DIs consist of clinically significant changes to the effect of a given drug caused by administration of another drug. Such changes may lead to modification of the absorption capacity to bind to proteins, or of the metabolic or excretion rate of one or even two of the medications involved in the interaction concerned. ${ }^{10,11}$ Faced with considerable increases in the proportion 
of drug prescriptions issued to older people and the consequent increased risk of adverse events among these individuals, there is concern regarding identification and prevention of undesirable combinations and use of PIMs.

It is known that PIMs increase the chances of adverse outcomes among older adults and that these are exacerbated when frailty syndrome is present. ${ }^{9,13,14}$ Nevertheless, studies in the scientific literature on this topic have focused on demonstrating the association between polypharmacy and frailty, ${ }^{15,16}$ but without including evaluations of DIs and PIMs. It is also worth mentioning that older people, including frail individuals, experience reduced efficacy of medications, in addition to higher risk of adverse effects. ${ }^{17}$ The possible explanations for this phenomenon include impaired physiological systems that combat frailty, drug interactions, drug-disease interactions and reduced adherence to medication. Additionally, adverse reactions to medications go unnoticed and can lead to other prescriptions. ${ }^{17}$

The existence of this gap in knowledge emphasizes the need for clarifications regarding the relationship of these variables with frailty syndrome among community-dwelling older people. Better knowledge of the implications arising from variables relating to use of drugs can improve preventive clinical approaches towards the embrittlement process among older people. This could lead to significant differences in quality of life during the aging process.

\section{OBJECTIVE}

The objective of this study was to evaluate the association between the use of drugs and frailty among community-dwelling older people.

\section{METHODS}

\section{Design}

This cross-sectional study consisted of a household survey conducted among older people living in the urban area of the city of Uberaba, Minas Gerais, in the southeastern region of Brazil. This study followed the guidelines of the Checklist for Reporting Results of Internet E-Surveys and the guidelines for Strengthening the Reporting of Observational Studies in Epidemiology (STROBE).

\section{Sample}

The sample size calculation considered a prevalence of frailty of $12.8 \%,{ }^{6}$ accuracy of $2.7 \%$ and a $95 \%$ confidence interval for a finite population of 36,703 older people. From this, the sample size was determined as 579 subjects. However, allowance was made for a sampling loss of $20 \%$ and therefore it was calculated that the maximum number of individuals to be approached would be 724 elderly people. To define the study population, a multistage cluster sampling process was used, considering census tracts, with information on neighborhoods and streets provided by the Brazilian Institute for Geography and Statistics. Tracts were drawn in order to subsequently select older people living in these tracts.

Older adults aged 60 or older, who were living in the urban area of the municipality and who were able to walk, were included in the study. It needs to be highlighted that, in Brazil, people aged 60 years or over are considered to be older adults, according to the current legislation. ${ }^{18}$

Subjects were excluded from this study in the following situations: presentation of cognitive decline, as assessed using the Mini Mental State Examination (MMSE); ${ }^{19}$ failure to locate the individual after three visits; hospitalization and/or institutionalization; and inability to undergo the assessment of frailty. This assessment because impossible if the subject presented inability to walk, severe sequelae from stroke, localized loss of strength and aphasia, or a severe or unstable stage of Parkinson's disease and associated severe impairment of motility, speech or cognition.

In the end, a total of 768 older people were approached, taking into account both the inclusion criteria and the losses, which comprised 154 due to cognitive decline and 34 due to incomplete tests for frailty evaluation. Hence, 580 patients were assessed in the present study.

\section{Data collection}

The interviews took place in the older people's homes, in the period from March to June 2016. They were conducted by trained interviewers with previous experience in collecting data. Five supervisors, who had previously been selected, checked the interviews to verify the filling out and consistency of the items, in order to ensure quality control.

\section{Explanatory and adjustment variables}

The explanatory and adjustment variables were collected using a structured questionnaire that sought the following information: (1) socioeconomic: age (numerical variable) and/or age group in years (60 to 69,70 to 79 and 80 or older); gender (male or female); marital status (with or without a partner); schooling, in years (no education, 1 to 4 years and 5 years or more); individual monthly income, in minimum wages (no income, $\leq$ 1 minimum wage and $>1$ minimum wage); and (2) number of self-reported morbidities ( 0,1 to 4 and 5 or more), as described in a previous study. ${ }^{20}$

\section{Frailty syndrome (dependent variable)}

Presence of frailty syndrome, which was taken to be the dependent variable, was identified through the five items that were proposed as components of the frailty phenotype by Fried et al.: 
1. Unintentional weight loss: assessed through the question: "In the last year, did you lose more than $4.5 \mathrm{~kg}$ without intention (that is, without dieting or exercise)?".

2. Self-report of exhaustion and/or fatigue: assessed through two questions from the Brazilian version of the Center for Epidemiological Studies (CES-D) depression scale, i.e. item 7 ("Did you feel you had to make an effort to cope with your usual tasks?") and item 20 ("Were you unable to carry on with your things?"). The elderly people with a score of 2 or 3 in either of these questions met the frailty criterion for this item. ${ }^{21}$

3. Decreased muscle strength, as assessed from handgrip strength using a manual hydraulic dynamometer (Model SH5001, SAEHAN, São Paulo, Brazil) and adopting the cutoff points proposed by Fried et al. ${ }^{1}$

4. Slow gait speed, obtained from the gait time (in seconds) that was needed to cover a distance of 4.6 meters, using the cutoff points proposed by Fried et al. ${ }^{1}$

5. Low level of physical activity, as ascertained from the long version of the International Physical Activity Questionnaire (IPAQ), adapted for older people.22 The classification used for this component considered older people to be inactive if they had 0-149 minutes of physical activity per week. ${ }^{23}$

The older people who were positive for three or more of these items were classified as frail and those who were positive for one or two items were classified as pre-frail. Those who were negative in all the tests were considered to be robust or non-frail. ${ }^{1}$

\section{Drug use (independent variables)}

To assess the variables relating to drug use, the older subjects were first asked: "Could you show me the medications you are currently using?" Thus, they were asked about their medical prescriptions and the packaging of the drugs that were being used at the time of data collection. The following were recorded: the pharmaceutical form of the medicinal products, the amounts consumed and the number of applications per day. Based on these data, situations of polypharmacy, DIs and PIMs were evaluated, as described below.

Polypharmacy was checked by counting the number of medications used by each older individual. When these older people reported using five or more medications, they were deemed to present polypharmacy. ${ }^{8}$

Occurrences of DIs were also assessed through the Micromedex Drug Reax System (Greenwood Village, Colorado, USA), using its online access platform, ${ }^{24}$ which contains evidence-based information on drugs and diseases. This tool allowed identification of the DIs that occurred (drug-drug) and ranked them according to severity (severe, moderate or mild). It is worth noting that this tool is widely recognized worldwide for use by healthcare professionals, including pharmacists, to obtain unbiased data. The value of this tool has been sustained through systematic reviews on the subject. ${ }^{24}$

Use of PIMs was classified in accordance with the criteria established in the Brazilian Consensus on Potentially Inappropriate Drugs for Older People. ${ }^{12}$ To analyze this variable, the subjects were divided between: "Using PIMs", when it was found that they were using at least one drug classified as inappropriate; and "Not using PIMs" when they did not use any of these drugs.

\section{Data analysis}

The data were entered into an electronic spreadsheet in the Excel software, in duplicate, in order to identify any possible inconsistencies from data entry. Subsequently, the data were imported into the Statistical Package for the Social Sciences (SPSS) software, version 22.0 (New Orchard Road, Armonk, New York, USA), to carry out the analyses.

A descriptive statistical analysis was conducted by distributing absolute and percentage frequencies. The bivariate analysis on the socioeconomic characteristics and variables relating to use of drugs according to frailty condition was done using the chi-square test. To assess associations among use of polypharmacy, PIMs and DIs in relation to the frailty syndrome, the logistic regression model was adopted. In this model, the outcome variable was recategorized so as to become dichotomous (frail/pre-frail versus non-frail). In the final adjusted model, the independent variables were included (polypharmacy, use of PIMs and DIs), along with other potential confounding variables such as gender, age, education and number of self-reported morbidities. For all analyses, the tests were considered significant when $\mathrm{P}<0.05$.

\section{Ethical considerations}

This study was approved by the human-research ethics committee of the Federal University of Triângulo Mineiro (Universidade Federal do Triângulo Mineiro, UFTM), under protocol no. 493,211, dated December 13, 2013.

\section{RESULTS}

Out of the total number of participants $(n=768), 154$ older people were excluded because they presented cognitive decline and 34 because of inability to perform the comprehensive evaluation of the components of the frailty phenotype. Thus, the final sample consisted of 580 older adults.

In comparing the older people who were excluded with those who participated in the study, it was found that for both groups, the majority were female (70.7\% versus $68.1 \% ; \mathrm{P}=0.418)$; were living without a partner $(71.3 \%$ versus $52.4 \% ; \mathrm{P}=0.353)$; had had one to four years of schooling ( 56.4 versus $52.6 \%$; $\mathrm{P}=0.352$ ); had a 
monthly income of less than or equal to two minimum salaries (88.2\% versus $81.6 \%$; $\mathrm{P}=0.979)$; and had five or more self-reported morbidities (64.7\% versus $62.4 \%$; $\mathrm{P}=0.493$ ). Regarding the age groups, older people aged 70 to 79 years (30.9\%) predominated among the excluded individuals; while older adults aged 60 to 69 years $(44.1 \%)$ predominated among those who participated in the study. However, there was no significant difference regarding age groups $(\mathrm{P}=0.645)$.

Based on the final sample $(n=580)$, the frailty status among the subjects was as follows: $13.1 \%(n=76)$ were frail; $55.7 \%(n=323)$ were pre-frail; and $31.2 \%(n=181)$ were non-frail.

It was found that most of the participants were female $(68.1 \%)$; were between 60 and 69 years old (44.1\%); were living without a partner (52.4\%); had had one to four years of schooling (52.6\%); and had a monthly income of two minimum wages (46.0\%), followed by $\leq 1$ minimum wage (44.7\%). In analyzing the sociodemographic variables according to the frailty classification, a higher percentage of older people aged 70 to 79 years $(\mathrm{P}<0.001)$ and with no education ( $\mathrm{P}=0.008$ ) was observed in the frail and pre-frail groups, compared with the non-frail group. It was also observed A higher proportion of older people with five or more frail and pre-frail morbidities was also observed, in relation to the non-frail ones $(\mathrm{P}=0.013)$ (Table $\mathbf{1})$.

Presence of polypharmacy was found in $31.7 \%(n=184)$ of the older people. It was found that $41.7 \%(n=242)$ had at least one DI and $43.8 \%(n=254)$ were using PIMs. Occurrence of these events was more common among the frail older people, among whom $51.3 \%(\mathrm{n}=39)$ presented polypharmacy $(\mathrm{P}<0.001), 60.5 \%(\mathrm{n}=46)$ had DIs $(\mathrm{P}=0.001)$ and 53.9\% $(\mathrm{n}=41)$ had PIM use $(\mathrm{P}<0.001)$, in comparison with the other groups (Figure 1).

In logistic regression analysis, it could be seen in the initial model that presence of polypharmacy (odds ratio, $\mathrm{OR}=1.91$; confidence interval, $\mathrm{CI}=1.27-2.86)$ and use of PIMs (OR $=2.45 ; \mathrm{CI}=$ 1.68-3.57) increased the odds of occurrence of frailty/pre-frailty among these community-dwelling older people. Evaluation of the final adjusted model showed that use of PIMs remained associated with increased chances of occurrence of frailty/pre-frailty $(\mathrm{OR}=$ 2.33, CI = 1.47-3.70), regardless of gender, age group, number of self-reported morbidities, education or other variables relating to use of medications (polypharmacy and DIs). It is noteworthy that age was also an explanatory variable for occurrences of frailty (Table 2).

\section{DISCUSSION}

The data from this study highlight that frailty among older people is a serious public health problem, given that significant prevalence (13.1\%) of this event among elderly individuals living in their own homes was demonstrated. This finding was similar to what has been found in other studies conducted in Brazil and worldwide that also used Fried's phenotype: $12.8 \%,{ }^{6} 14.8 \%,{ }^{25} 10 \%{ }^{26}$ and $14 \% .{ }^{27}$ However, it differed from others that have identified higher prevalences $\left(47 \%{ }^{28}\right.$ and $65.25 \%{ }^{29}$ ) through using the Tilburg Frailty Indicator (TFI) concept and instrument.

This divergence of results was expected, given that the prevalence of frailty may vary according to the diagnostic instrument,

Table 1. Absolute and percentage frequency distributions of the sociodemographic and health variables of the elderly subjects, according to their frailty phenotype classification; Brazil, 2016

\begin{tabular}{|c|c|c|c|c|c|c|}
\hline \multirow[b]{2}{*}{ Variables } & & \multicolumn{3}{|c|}{ Frailty phenotype } & \multirow{2}{*}{$\begin{array}{l}\text { Total } \\
\%(n)\end{array}$} & \multirow[b]{2}{*}{$P^{*}$} \\
\hline & & $\begin{array}{c}\text { Non-frail } \\
\%(n)\end{array}$ & $\begin{array}{c}\text { Pre-frail } \\
\%(n)\end{array}$ & $\begin{array}{l}\text { Frail } \\
\%(n)\end{array}$ & & \\
\hline \multirow{2}{*}{ Gender } & Male & $30.4(55)$ & $34.4(111)$ & $25.0(19)$ & $31.9(185)$ & \multirow{2}{*}{0.252} \\
\hline & Female & $69.6(126)$ & $65.6(212)$ & $75.0(57)$ & $68.1(395)$ & \\
\hline \multirow{3}{*}{ Age group (in years) } & 60 to 69 & 59.1 (107) & $39.3(127)$ & $28.9(22)$ & $44.1(256)$ & \multirow{3}{*}{$<0.001$} \\
\hline & 70 to 79 & $35.4(64)$ & $42.4(137)$ & $38.2(29)$ & $39.7(230)$ & \\
\hline & 80 or older & $5.5(10)$ & $18.3(59)$ & $32.9(25)$ & $16.2(94)$ & \\
\hline \multirow{2}{*}{ Marital status } & Companion & $48.1(87)$ & $52.6(170)$ & $47(61.8)$ & $304(52.4)$ & \multirow{2}{*}{0.130} \\
\hline & No companion & $51.9(94)$ & $47.4(153)$ & $29(38.2)$ & $276(47.6)$ & \\
\hline \multirow{3}{*}{$\begin{array}{l}\text { Education } \\
\text { (years of schooling) }\end{array}$} & No education & $11.6(21)$ & $16.1(52)$ & $23.7(18)$ & $15.7(91)$ & \multirow{3}{*}{0.008} \\
\hline & 1 to 4 & $47.5(86)$ & $55.7(180)$ & $51.3(39)$ & $52.6(305)$ & \\
\hline & 5 or more & $40.9(74)$ & $28.2(91)$ & $25.0(19)$ & $31.7(184)$ & \\
\hline \multirow{3}{*}{ Monthly income } & No income & $11.6(21)$ & $9.0(29)$ & $5.3(4)$ & $9.3(54)$ & \multirow{3}{*}{0.132} \\
\hline & $\leq 1$ minimum wage & $39.8(72)$ & $44.6(144)$ & $56.6(43)$ & 44.7 (259) & \\
\hline & $>2$ minimum wages & $48.6(88)$ & $46.4(150)$ & $38.2(29)$ & $46.0(267)$ & \\
\hline \multirow{3}{*}{ Number of morbidities } & 0 & $4.4(8)$ & $1.3(4)$ & $0(0)$ & $2.1(12)$ & \multirow{3}{*}{0.013} \\
\hline & 1 to 4 & $37.6(68)$ & 36.8 (119) & $25.0(19)$ & 35.5 (206) & \\
\hline & 5 or more & $58.0(105)$ & $61.9(200)$ & $75.0(57)$ & $62.4(362)$ & \\
\hline
\end{tabular}

*Chi-square test. 
methodological standardization, plurality of existing concepts and variability of sample composition. ${ }^{30}$ A systematic review by Collard et al. showed that there was marked variation in the prevalence of frailty among community-dwelling older people, from $4.0 \%$ to $59.1 \% .{ }^{31}$ These data emphasize the need for these differences to be considered not only by healthcare professionals in evaluating older

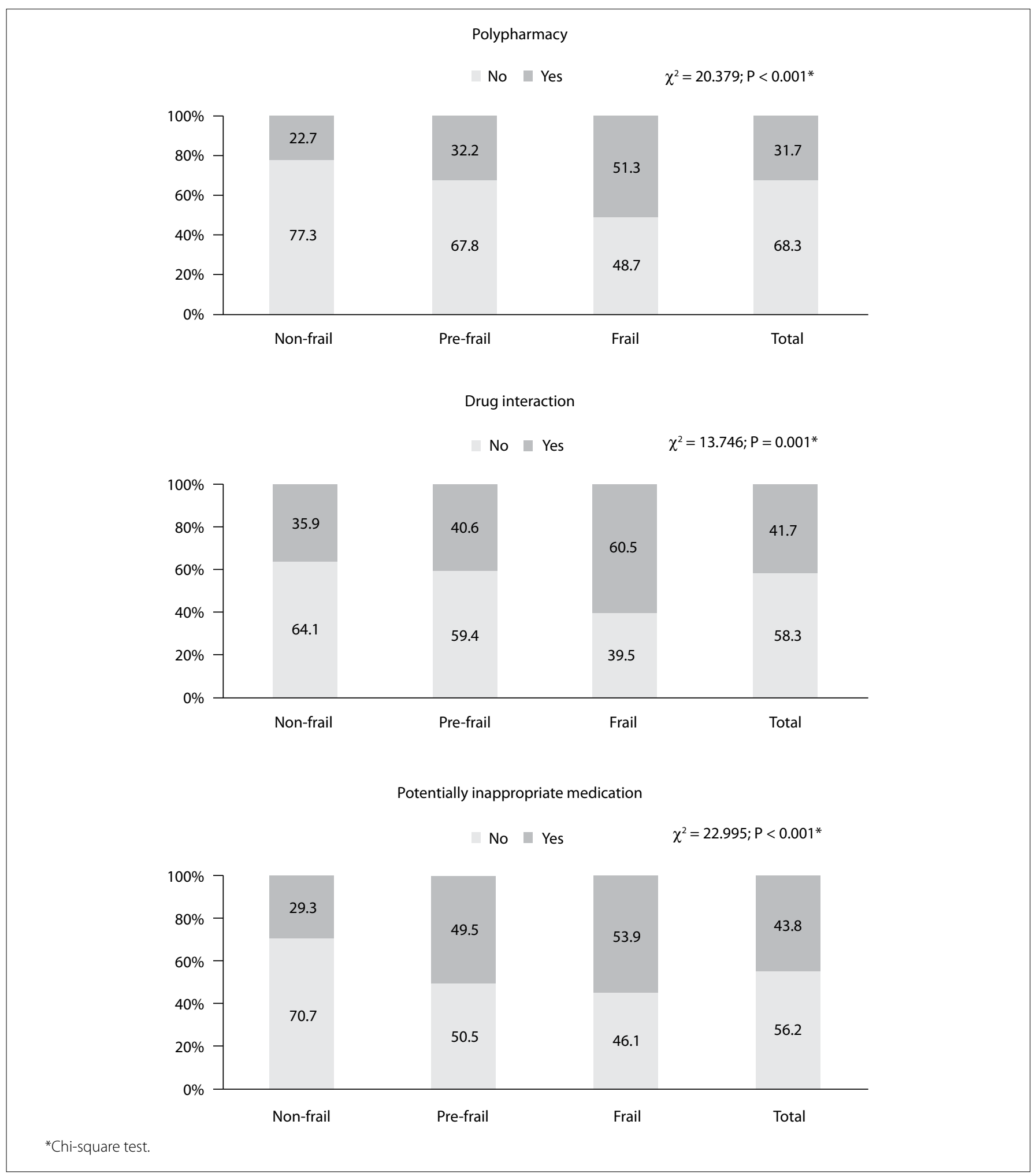

Figure 1. Occurrences (\%) of polypharmacy, drug interaction and use of potentially inappropriate medication for elderly people, according to the frailty phenotype classification; Brazil, 2016. 
people within clinical practice but also by managers in formulating public health policies. ${ }^{31}$

Since drug prescription is a participant in the frailty process, its quality requires special attention from healthcare professionals. The aging process makes older people more susceptible to developing chronic conditions, which eventually leads to use of several medications concomitantly. ${ }^{9}$ This, together with the pharmacokinetic and pharmacodynamic changes that occur with advancing age, results in exacerbated adverse effects, especially when the frailty syndrome is present. ${ }^{9,32}$

These results converge with findings that were highlighted by other researchers, through demonstration of the association between polypharmacy and frailty in the initial logistic regression model. ${ }^{15,16,33}$ According to the International Frailty Consensus, polypharmacy is a possible cause of increased pathogenesis of frailty. Hence, reduction of the use of drugs for older people is recommended, among other clinical guidelines. ${ }^{7}$ A longitudinal study on Japanese older people found that those who used six or more drugs were at higher risk of developing frailty, in relation to the others, over a six-year period. ${ }^{34}$ It is worth considering, however, that polypharmacy did not remain associated with an increased chance of frailty in the adjusted model of the present study, and this was also seen in other studies. ${ }^{29,35}$ These data highlight the importance of including other variables associated with evaluation of the quality of drug use among older people within clinical practice.

The relationship between DI and frailty was also analyzed in the present study but no significant association was found, either in the initial logistic regression model or in the adjusted model. Pagno et al. found that $52.2 \%$ of the older people were exposed to DIs, which was a result similar to that of the present study. They also found that most older people with DIs were classified as frail (68.2\%) and demonstrated that exposure of older people to DIs increased the chance of this outcome. However, they did not carry out multivariate analysis with adjustment for other variables. ${ }^{33}$ It is important to note that most of the researchers who have evaluated DIs among older people did not consider frailty to be a factor associated with this event, as seen in an integrative review of the literature conducted by Rodrigues and Oliveira. ${ }^{3}$ Hence, there is a need for further clarification of this relationship through additional studies.

In the current study, use of PIMs was the independent variable that explained the increased chances of occurrence of frailty, thus confirming other findings that have been described in the literature. ${ }^{33,36-39}$ The hypotheses that might contribute towards understanding this association include the following:

a) Use of PIMs can worsen older people's clinical state, thereby interfering with their quality of life and increasing the magnitude of adverse health outcomes; ${ }^{12,33}$ and these occurrences are exacerbated when frailty syndrome is present. ${ }^{9,13,14}$

b) Among the adverse outcomes relating to use of PIMs, a strong association with functional decline has been shown; ${ }^{36}$ this is significantly correlated with frailty syndrome, as shown by Fried et al. ${ }^{1}$

c) PIMs can affect the components that are measured in the frailty phenotype, such as weakness, low gait speed or low levels of physical activity. ${ }^{1,36}$

The findings of the current study demonstrated that use of PIMs was highly prevalent among these community-dwelling

Table 2. Logistic regression models to verify associations among polypharmacy, drug interaction and use of potentially inappropriate medications in relation to the elderly frailty phenotype, Brazil, 2016

\begin{tabular}{|c|c|c|c|c|c|}
\hline & & & & & \\
\hline & & & & & odel \\
\hline Polynharmary & No & 1 & 1 & 1 & 1 \\
\hline DI & No & 1 & 1 & 1 & 1 \\
\hline DI & Yes & 1.42 & $0.99-2,04$ & 0.77 & $0.46-1.28$ \\
\hline & Female & - & - & 1 & 1 \\
\hline Gender & Male & - & - & 0.79 & $0.52-1.21$ \\
\hline Age & - & - & - & $1.08^{\ddagger}$ & $1.05-1.11^{\ddagger}$ \\
\hline & No education & & & & \\
\hline Education & 1 to 4 years & & & 0.79 & $0.58-1.04$ \\
\hline
\end{tabular}

Reference category $=$ non-frail; $\neq \mathrm{P}<0.001 ; 1=$ reference category.

$\mathrm{OR}=$ odds ratio; $\mathrm{Cl}=$ confidence interval; $\mathrm{DI}=$ drug interactions. 
older people and that its presence was associated with occurrences of frailty. These findings are concordant with the clinical guidance for management of frailty, in which reduction or deprescription of potentially inappropriate medication for older adults is strongly recommended. ${ }^{40}$ Curtin et al. used the STOPPFrail criteria and demonstrated that this is a tool that removes an important barrier against deprescription of medications through explicitly highlighting the circumstances in which commonly used medications can be safely deprescribed among older people with advanced frailty. ${ }^{41}$

Professionals working within primary healthcare are in closer contact with community-dwelling older people and, therefore, should incorporate evaluation of use of PIMs in their overall routine for geriatric assessment. In this regard, the International Frailty Consensus recommends use of the Beers and STOPPFrail criteria within clinical practice. When use of PIMs is identified, the older individuals presenting this usage should be referred for medical evaluation, in order to optimize their medication treatment and, therefore, prevent frailty syndrome. Lavan et al. found that almost $65 \%$ of their patients awaiting long-term care were eligible for application of the STOPPFrail criteria, such that over $90 \%$ of these had been prescribed at least one PIM. They concluded that the transition to nursing-home care represented an opportunity to review the therapeutic appropriateness and goals of the medications that had been prescribed for these individuals. ${ }^{42}$

Although use of PIMs was the only explanatory independent variable for frailty syndrome in the present study, the importance of evaluating polypharmacy and DIs cannot be overlooked. It is known that both the presence of PIM and the presence of polypharmacy tend to make frail older people more prone to negative events, such as increased risk of adverse effects, mostly coming from DIs. These relationships can be explained in terms of the changes and features present in frail older people that make them more vulnerable to manifestations of DIs and health problems arising from them. ${ }^{33,43,44}$

In addition, several studies have shown that use of multiple medications is associated with use of PIMs. ${ }^{38,45-51}$ Other authors have shown, however, that the risk of using PIMs is greater among individuals with higher numbers of morbidities and who, thus, have to use more drugs. ${ }^{48,52,53}$ Pagno et al. also identified that the prevalence of frailty was higher in the presence of PIMs that were involved in DIs. ${ }^{33}$ Moreover, Lorenzo-López et al. confirmed the dynamics of frailty and the bidirectional nature of frailty transitions, thus indicating the need for prevention and treatment of these conditions in later life, in order to minimize the burden of frailty. ${ }^{54}$

The findings from the present study need to be considered cautiously due to its cross-sectional nature, which did not allow cause-and-effect relationships to be established among the variables. Moreover, it needs to be borne in mind that a self-report questionnaire was used to investigate morbidities, which meant that some of the information found may have been underestimated or overestimated. Therefore, use of cohort studies among community-dwelling older people is suggested, in order to assess the effect of interactions among the variables of DI, PIM and polypharmacy, regarding occurrences of frailty syndrome.

\section{CONCLUSION}

It was found that use of inappropriate medications was the independent variable that explained the occurrences of frailty in this representative sample of community-dwelling older people in a Brazilian municipality. However, this study showed that there is a need for research with a longitudinal design, in order to assess the causality of these conditions in relation to frailty.

Nevertheless, the data obtained in this study constitute an advance in this field of knowledge, since they indicate the need for advanced practices, with application of explicit methods for evaluation of drug use within primary healthcare, with a view to improving the quality of life of older people living in their own homes. Thus, in clinical practice, accurate analysis with the use of validated tools and technologies for monitoring and recognition of polypharmacy, potential drug interactions and inappropriate use of drugs can optimize the adequacy of prescription and hence minimize problems relating to these medications, thereby diminishing the onset of frailty.

\section{REFERENCES}

1. Fried $L P$, Tangen $C M$, Walston J, et al. Frailty in older adults: evidence for a phenotype. J Gerontol. 2001;56(3):M146-56. PMID: 11253156; doi: 10.1093/gerona/56.3.M146.

2. Fabrício-Wehbe SC, Rodrigues RA, Haas VJ, et al. Association of frailty in hospitalized and institutionalized elderly in the community-dwelling. Rev Bras Enferm. 2016;69(4):691-6. PMID: 27508474; doi: 10.1590/00347167.2016690411i.

3. Rodrigues MCS, Oliveira CD. Drug-drug interactions and adverse drug reactions in polypharmacy among older adults: an integrative review. Rev Lat Am Enfermagem. 2016;24:e2800. PMID: 27598380; doi: 10.1590/1518-8345.1316.2800.

4. Davies EA, O'Mahony MS. Adverse drug reactions in special populations - the elderly. Br J Clin Pharmacol. 2015;80(4):796-807. PMID: 25619317; doi: 10.1111/bcp.12596.

5. Lana LD, Schneider RH. The frailty syndrome in elderly: a narrative review. Rev Bras Geriatr Gerontol. 2014;17(3):673-80. doi: 10.1590/18099823.2014.12162.

6. Pegorari MS, Tavares DMS. Fatores associados à síndrome de fragilidade em idosos residentes em área urbana. Rev Latino-Am Enfermagem. 2014;22(5):874-82. doi: 10.1590/0104-1169.0213.2493. 
7. Morley JE, Vellas B, Van Kan GA, et al. Frailty consensus: a call to action. J Am Med Dir Assoc. 2013;14(6):392-7. PMID: 23764209; doi: 10.1016/j. jamda.2013.03.022.

8. Hovstadius B, Petersson G. Factors leading to excessive polypharmacy. Clin Geriatr Med. 2012;28(2):159-72. PMID: 22500536; doi: 10.1016/j. cger.2012.01.001.

9. Poudel A, Peel NM, Nissen LM, et al. Adverse Outcomes in Relation to Polypharmacy in Robust and Frail Older Hospital Patients. J Am Med Dir Assoc. 2016;17(8):767.e9-767.e13. PMID: 27373672; doi: 10.1016/j. jamda.2016.05.017.

10. Gnjidic D, Hilmer SN. Use of potentially inappropriate medications in the care of frail older people. Aging Health. 2010;6(6):705-16. doi: 10.2217/ahe.10.78.

11. Oates JA. The science of drug therapy. In: Brunton LL. Goodman \& Gilman's The pharmacological basis of therapeutics. $11^{\text {th }}$ ed. New York: McGraw-Hill; 2006. p. 77.

12. Oliveira MG, Amorim WW, Oliveira CRB, et al. Consenso brasileiro de medicamentos potencialmente inapropriados para idosos [Brazilian consensus of potentially inappropriate medication for elderly people]. Geriatr Gerontol Aging. 2016; 10(4): 168-181; doi: 10.5327/z2447211520161600054.

13. Lavan AH, O'Mahony D, Gallagher P. STOPPFrail (Screening Tool of Older Persons' Prescriptions in Frail adults with a limited life expectancy) criteria: application to a representative population awaiting long-term nursing care. Eur J Clin Pharmacol. 2019;75(5):723-31. PMID: 30685856; doi: 10.1007/s00228-019-02630-3.

14. Granas AG, Stendal Bakken M, Ruths S, Taxis K. Deprescribing for frail older people - Learning from the case of Mrs. Hansen. Res Social Adm Pharm. 2018;14(6):612-6. PMID: 28733142; doi: 10.1016/j.sapharm.2017.07.003.

15. Saum KU, Schöttker B, Meid AD, et al. Is Polypharmacy Associated with Frailty in Older People? Results from the ESTHER Cohort Study. J Am Geriatr Soc. 2016;65(2):e27-e32. PMID: 28024089; doi: 10.1111/ jgs. 14718 .

16. Veronese N, Stubbs B, Noale M, et al. Polypharmacy is associated with higher frailty risk in older people: an 8-year longitudinal cohort study. J Am Med Dir Assoc. 2017;18(7):624-8. PMID: 28396180; doi: 10.1016/j. jamda.2017.02.009.

17. Woodford HJ, Fisher J. New horizons in deprescribing for older people. Age Ageing. 2019;48(6):768-75. PMID: 31595290; doi: 10.1093/ageing/ afz109.

18. Brasil. Lei no 10.741 de 01 de outubro de 2003. Dispõe sobre o Estatuto do Idoso e dá outras providências. Diário Oficial da União, Brasília. Available from: http://www.planalto.gov.br/ccivil_03/leis/2003/l10.741. htm. Accessed in 2020 (Jul 2).

19. Bertolucci PHF, Brucki SMD, Campacci SR, et al. O Mini-Exame do Estado Mental em uma população geral: impacto da escolaridade [The Mini-Mental State Examination in an outpatient population: influence of literacy]. Arq Neuro-Psiquiatr. 1994;52(1):01-07. doi: 10.1590/S0004282X1994000100001.
20. Tavares DMDS, Pelizaro PB, Pegorari MS, Paiva MM, Marchiori GF. Prevalência de morbidades autorreferidas e fatores associados entre idosos comunitários de Uberaba, Minas Gerais, Brasil [Prevalence of self-reported morbidities and associated factors among community-dwelling elderly in Uberaba, Minas Gerais, Brazil]. Cien Saude Colet. 2019;24(9):3305-3313. doi: 10.1590/141381232018249.31912017.

21. Batistoni SST, Neri AL, Cupertino APFB. Validade da escala de depressão do Center for Epidemiological Studies entre idosos brasileiros [Validity of the Center for Epidemiological Studies Depression Scale Among Brazilian Elderly]. Rev Saude Publica. 2007;41(4):598-605. PMID: 17589758; doi: 10.1590/S0034-89102007000400014.

22. Mazo GZ, Benedetti TRB. Adaptação do questionário internacional de atividade física para idosos [Adaptation of the international physical activity questionnaire for the elderly]. Rev Bras Cineantropom Desempenho Hum. 2010;12(6):480-4. doi: 10.1590/S198000372010000600013.

23. Pate RR, Pratt M, Blair SN, et al. Physical activity and public health. A recommendation from the Centers for Disease Control and Prevention and the American College of Sports Medicine. JAMA. 1995;273(5):402-7. PMID: 7823386; doi: 10.1001/jama.1995.03520290054029.

24. Micromedex Health care Series [Internet]. Greenwood Village: Thomson Reuters (Healthcare); 2011. Available from: https://www. micromedexsolutions.com/home/dispatch. Accessed in 2020 (Jul 27).

25. Herr M, Sirven N, Grondin H, Pichetti S, Sermet C. Frailty, polypharmacy, and potentially inappropriate medications in old people: findings in a representative sample of the French population. Eur J Clin Pharmacol. 2017;73(9):1165-72. PMID: 28601963; doi: 10.1007/ s00228-017-2276-5.

26. Yamada $Y$, Nanri $H$, Watanabe $Y$, et al. Prevalence of Frailty Assessed by Fried and Kihon Checklist Indexes in a Prospective Cohort Study: Design and Demographics of the Kyoto-Kameoka Longitudinal Study. J Am Med Dir Assoc. 2017;18(8):733.e7-733.e15. PMID: 28501417; doi: 10.1016/j.jamda.2017.02.022

27. Gale CR, Cooper C, Sayer AA. Prevalence of frailty and disability: findings from the English Longitudinal Study of Ageing. Age Ageing. 2015;44(1):162-5. PMID: 25313241; doi: 10.1093/ageing/afu148.

28. Gobbens RJ, Van Assen MA, Luijkx KG, Wijnen-Sponselee MT, Schols JM. Determinants of Frailty. J Am Med Dir Assoc. 2010;11(5):356-64. PMID: 20511103; doi: 10.1016/j.jamda.2009.11.008.

29. Neves AQ, Silva AMC, Cabral JF, et al. Prevalence of and factors associated with frailty in elderly users of the Family Health Strategy. Rev Bras Geriatr Gerontol. 2018;21(6):680-90. doi: 10.1590/198122562018021.180043.

30. Carneiro JA, Ramos GC, Barbosa AT, et al. Prevalência e fatores associados à fragilidade em idosos não institucionalizados [Prevalence and factors associated with frailty in non-institutionalized older adults]. Rev. Bras. Enferm. 2016;69(3):435-42. PMID: 27355291; doi: https://doi. org/10.1590/0034-7167.2016690304i. 
31. Collard RM, Boter H, Schoevers RA, Oude Voshaar RC. Prevalence of frailty in community-dwelling older persons: a systematic review. J Am Geriatr Soc. 2012; 60(8):1487-92. PMID: 22881367; doi: 10.1111/j.15325415.2012.04054.x.

32. Hubbard RE, O'Mahony MS, Woodhouse KW. Medication prescribing in frail older people. Eur J Clin Pharmacol, 2013;69(3):319-26. PMID: 22965651; doi: 10.1007/s00228-012-1387-2.

33. Pagno AR, Gross CB, Gewehr DM, et al. A terapêutica medicamentosa, interações potenciais e iatrogenia como fatores relacionados à fragilidade em idosos [Drug therapy, potential interactions and iatrogenesis as factors related to frailty in the elderly]. Rev Bras Geriatr Gerontol. 2018;21 (5):588-96. doi: 10.1590/1981-22562018021.180085.

34. Yuki A, Otsuka R, Tange C, et al. Polypharmacy is associated with frailty in Japanese community-dwelling older adults. Geriatr Gerontol Int. 2018;18(10):1497-500. PMID: 30168240; doi: 10.1111/ggi.13507.

35. Santiago LM, Mattos IE. Prevalência e fatores associados à fragilidade em idosos institucionalizados das regiões Sudeste e Centro-Oeste do Brasil [Prevalence and factors associated to frailty in institutionalized elderly of Southeastern and Middle-Western Brazil]. Rev Bras Geriatr Gerontol. 2014;17(2):327-37. doi: 10.1590/S1809-98232014000200010.

36. Muhlack DC, Hoppe LK, Stock C, et al. The associations of geriatric syndromes and other patient characteristics with the current and future use of potentially inappropriate medications in a large cohort study. Eur J Clin Pharmacol. 2018;74(12):1633-44. PMID: 30159676; doi: 10.1007/s00228-018-2534-1.

37. Cullinan S, O'Mahony D, O'Sullivan D, Byrne S. Use of a frailty index to identify potentially inappropriate prescribing and adverse drug reaction risks in older patients. Age Ageing. 2016;45(1):115-20. PMID: 26683048; doi: 10.1093/ageing/afv166.

38. Cassoni TC, Corona LP, Romano-Lieber NS, et al. Uso de medicamentos potencialmente inapropriados por idosos do Município de São Paulo, Brasil: Estudo SABE [Use of potentially inappropriate medication by the elderly in São Paulo, Brazil: SABE Study]. Cad. Saude Publica. 2014;30(8):1708-20. PMID: 25210910; doi: 10.1590/0102$311 \times 00055613$.

39. Bolina AF, Gomes NC, Marchiori GF, Pegorari MS, Tavares DMDS. Potentially inappropriate medication use and frailty phenotype among community-dwelling older adults: A population based study. J Clin Nurs. 2019;28(21-22):3914-22. PMID: 31240751; doi: 10.1111/ jocn. 14976.

40. Dent E, Lien C, Lim WS, et al. The Asia-Pacific clinical practice guidelines for the management of frailty [published correction appears in J Am Med Dir Assoc. 2018 Jan;19(1):94]. J Am Med Dir Assoc. 2018;18(7):56475. PMID: 28648901; doi: 10.1016/j.jamda.2017.04.018.

41. Curtin D, DukelowT, James K, et al. Deprescribing in multi-morbid older people with polypharmacy: agreement between STOPPFrail explicit criteria and gold standard deprescribing using 100 standardized clinical cases. Eur J Clin Pharmacol. 2019;75(1):427-32. PMID: 30421220; doi: $10.1007 / 500228-018-2598-y$
42. Lavan AH, Gallagher P, Parsons C, O'Mahony D. STOPPFrail (Screening Tool of Older Persons Prescriptions in Frail adults with limited life expectancy): consensus validation. Age Ageing. 2017;46(4):600-7. PMID: 28119312; doi: 10.1093/ageing/afx005.

43. Secoli SR. Polifarmácia: interações e reações adversas no uso de medicamentos por idosos [Polypharmacy: interaction and adverse reactions in the use of drugs by elderly people]. Rev Bras Enferm. 2010;63(1):136-40. PMID: 20339769; doi: 10.1590/S003471672010000100023.

44. Vieira RA, Guerra RO, Giacomin KC, et al. Prevalência de fragilidade e fatores associados em idosos comunitários de Belo Horizonte, Minas Gerais, Brasil: dados do estudo FIBRA. [Prevalence of frailty and associated factors in community-dwelling elderly in Belo Horizonte, Minas Gerais State, Brazil: data from the FIBRA study] [published correction appears in Cad Saude Publica. 2013 Nov;29(11):2357]. Cad Saude Publica. 2013;29(8):1631-43. PMID: 24005928; doi: 10.1590/0102$311 \times 00126312$.

45. Baldoni Ade O, Ayres LR, Martinez EZ, et al. Factors associated with potentially inappropriate medications use by the elderly according to Beers criteria 2003 and 2012. Int J Clin Pharm. 2014; 36(2):316-24. PMID: 24271923; doi: 10.1007/s1 1096-013-9880-y.

46. Buck MD, Atreja A, Brunker $C P$, et al. Potentially inappropriate medication prescribing in outpatient practices: prevalence and patient characteristics based on electronic health records. Am J Geriatr Pharmacother. 2009;7(2):84-92. PMID: 19447361; doi: 10.1016/j. amjopharm.2009.03.001.

47. Gallagher PF, Barry PJ, Ryan C, Hartigan I, O'Mahony D. Inappropriate prescribing in an acutely ill population of elderly patients as determined by Beers'Criteria. Age Ageing, 2008;37(1):96-101. PMID: 17933759; doi: 10.1093/ageing/afm116.

48. Gallagher P, Lang PO, Cherubini A, et al. Prevalence of potentially inappropriate prescribing in an acutely ill population of older patients admitted to six European hospitals. Eur J Clin Pharmacol. 2011;67(11):1175-88. PMID: 21584788; doi: 10.1007/s00228-011-1061-0.

49. Gavilán ME, Morales Suárez-Varela MT, Hoyos Esteban JA, Pérez Suanes AM. Polimedicación y prescripción de fármacos inadecuados en pacientes ancianos inmovilizados que viven en la comunidad [Inappropriate multiple medication and prescribing of drugs in immobile elderly patients living in the community]. Aten Primaria. 2006;38(9):476-82. PMID: 17194349; doi: 10.1157/13095047.

50. Holguín-Hernández E, Orozco-Díaz JG. Medicación potencialmente inapropiada en ancianos en un hospital de primer nivel, Bogotá 2007 [Potentially inappropriate medication in elderly in a first level hospital, Bogota 2007]. Rev Salud Publica (Bogota). 2010;12(2):287-99. PMID: 21031239; doi: 10.1590/s0124-00642010000200012.

51. Oliveira MG, Amorim WW, de Jesus SR, Rodrigues VA, Passos LC. Factors associated with potentially inappropriate medication use by the elderly in the Brazilian primary care setting. Int J Clin Pharm. 2012;34(4):626-32. PMID: 22692715; doi: 10.1007/s1 1096-012-9656-9. 
52. Blalock SJ, Byrd JE, Hansen RA, et al. Factors associated with potentially inappropriate drug utilization in a sample of rural community-dwelling older adults. Am J Geriatr Pharmacother. 2005;3(3):168-79. PMID: 16257819; doi: 10.1016/S1543-5946(05)80023-6

53. Rozenfeld S, Fonseca MJ, Acurcio FA. Drug utilization and polypharmacy among the elderly: a survey in Rio de Janeiro City, Brazil. Rev Panam Salud Publica, 2018;23(1):34-43. PMID: 18291071; doi: 10.1590/s102049892008000100005.

54. Lorenzo-López L, López-López R, Maseda A, et al. Changes in frailty status in a community-dwelling cohort of older adults: The VERISAÚDE study. Maturitas, 2019;119:54-60. PMID: 30502751; doi: 10.1016/j. maturitas.2018.11.006.

Authors' contributions: Alves MKL: conceptualization (equal), methodology (equal), writing-original draft (equal) and writing-review and editing (equal); Oliveira NGN: data curation (equal), methodology (equal), writing-original draft (equal) and writing-review and editing (equal); Pegorari MS: data curation (equal), methodology (equal), writingoriginal draft (equal) and writing-review and editing (equal); Tavares DMS: funding acquisition (equal), methodology (equal), writing-original draft (equal) and writing-review and editing (equal); Rodrigues MCS: methodology (equal), writing-original draft (equal) and writing-review and editing (equal); and Bolina AF: conceptualization, formal analysis (equal), methodology, project administration (equal), writing-original draft (equal) and writing-review and editing (equal). All authors actively contributed to the discussion of the results of the study, reviewed it and approved the final version to be released

Sources of funding: Conselho Nacional de Desenvolvimento Científico

e Tecnológico (CNPq), Brazil, procedural number 301704/2012-0; and

Fundação de Amparo à Pesquisa do Estado de Minas Gerais (FAPEMIG),

Brazil, procedural number APQ-00866-12

Conflict of interest: None

Date of first submission: May 1, 2020

Last received: July 28, 2020

Accepted: August 6, 2020

\section{Address for correspondence:}

Alisson Fernandes Bolina

Universidade de Brasília

Asa Norte, s/no

Campus Darcy Ribeiro — Brasília (DF) — Brasil

CEP 70910-900

Tel. (+55 61) 3107-1702

E-mail: alissonbolina@yahoo.com.br 